\title{
Effect of Administration of Fatless Probiotic Food Containing Whey Protein Concentrate on the Faecal Count, Blood Cholesterol Level and Growth Performance of Albino Rats
}

\author{
P.K. Bisoi ${ }^{1}$, Rakesh Kumar ${ }^{2}$, Binita Rani $^{3}$ and B.K. Singh ${ }^{4 *}$ \\ ${ }^{1}$ Dairy Microbiology, OUAT, Bhubneshwar, India \\ ${ }^{2}$ Department of Dairy Microbiology, ${ }^{3}$ Dairy Nutrition, ${ }^{4}$ Dairy Technology, Faculty of Dairy \\ Technology, SGIDT, Jagdeo Path, Patna, Bihar, India \\ *Corresponding author
}

\section{A B S T R A C T}

\section{Keywords}

Nonfat fermented milk, Whey protein concentrate, Lactobacillus acidophilus, Lactobacillus casei, Albino rats

Article Info

Accepted:

04 January 2018

Available Online:

10 February 2018
Increased industrialization, urbanization and mechanization are being associated with the dramatic changes in perception of health beneficial food which in turn has led to a significant decrease in the occurrence of chronic non-communicable diseases viz. obesity, diabetes-mellitus, cardiovascular diseases, stroke and hypertension and some types of cancer. Fatless fermented milk added with whey protein concentrate at $3 \%$ level was prepared by inoculating $1 \%$ inoculum of Lactobacillus acidophilus- 015 and Lactobacillus casei-297 at 1:1 ratio and fed to albino rats for 45 days. Lactic count in faecal material and body weight of experimental animal were more increased in Group III rats which were fed whey protein concentrate added fatless fermented milk as compare to Group II rats which were fed plain fatless fermented milk than control group-I rats at the end of experiment. Coliform count in faecal material and serum cholesterol level were declined more in Group III rats comparatively to Group II rats than control Group-I rats whereas cholesterol level was increased in control group rats at the end of the experiment. So, it can be recommended to use of WPC as prebiotic in the preparation of fat less fermented milk products for maintaining the bacterial environment of intestine and controlling blood cholesterol level.

\section{Introduction}

Fermented dairy products have been playing a major role in the part of the diet of people throughout the world for their taste, nutritive value and therapeutic properties. During recent years, an increasing interest has developed in foods that contribute to a positive effect on health beyond their nutritional value. Among these functional foods, much attention has been focused on probiotic products. Probiotic foods contain microorganisms or components of microbial cells that have a beneficial effect on the health and well-being of the consumer host (Salminen et al., 1999). Sometimes the probiotic organisms fail to grow properly and to fight against pathogenic organisms due to lack of their foods. This has led to the coining of the term synbiotic food, which includes 
probiotic microorganisms and their food materials known as prebiotic substances in the system. Klaver and Van der Meer (1993) suggested that probiotic organisms assimilate cholesterol within bacterial cell, increased excretion of bile salts due to deconjugation by bile salt hydrolase, antioxidative effect. Kawase et al., (2000) found that Lactic acid bacteria inhibit the cholesterol absorption by binding of cholesterol to lactic acid bacterial cells, the promotion of excretion through faeces by the binding of bile acid to lactic acid bacterial cells and the assimilation of cholesterol by lactic acid bacteria. Oyetayo et al., (2003) investigated that Lactobacillus casei had a better probiotic effect than Lactobacillus acidophilus in terms of live function improvement, anticholesterolaemic property and protection of the gastrointestinal tract from infection. Yadav et al., (2008) reported that Lactobacillus acidophilus and Lactobacillus casei significantly increased the counts of Lactobacilli adherent to epithelial walls and free in the lumen of the small and large intestine, while decreasing attached as well as free coliform counts. Nagaoka (1996) described that $\beta$-lactoglobulin inhibited cholesterol absorption through changes of micellar cholesterol solubility in the intestine, accompanied by an increase of faecal steroid excretion.

Newburg et al., (1998) investigated that whey protein concentrate might have enhanced the immune response to rotavirus challenge bacterial action because of immunoglobulin and reduced pathogenically clearance time by increasing neutrophil or natural killer cell activity. Naidu et al., (1999) found that stalic acids (types of oligosaccharides) are typically attached to whey proteins and possess the prebiotic effects. Naidu et al., (1999) suggested that whey contains several unique components including Lactose, Immunoglobulin, Lactoferrin, Lactoperoxidase, Glycomacro peptides and
Sphingoloipids and significant levels of these survive passage through the stomach and small intestine and survive in the large intestine and intact proteins, where they exert their biological effects. Walzem et al., (2002) found that whey protein content about $26 \%$ of branched chain amino acids which stimulated protein synthesis and muscle building. The present investigation was conducted to exploit the prebiotic character of whey protein concentrate with selected probiotics for maintaining the gastro-intestinal environment as well as controlling blood cholesterol level.

\section{Materials and Methods}

Two strains of lactic acid bacteria in freeze dried ampules namely Lactobacillus acidophilus-015 and Lactobacillus casei-297 were obtained from national collection of dairy culture centre, NDRI, Karnal, India. Both the cultures were maintained in sterile litmus milk media having reconstituted skim milk (10\%) $100 \mathrm{ml}, 1$ percent litmus solution 1-2 $\mathrm{ml}$ and final $\mathrm{pH} 1.0$, and then activated by three successive transfers at $24 \mathrm{~h}$ interval before use. Purity of the organisms was confirmed before use by microscopic examination using Gram staining technique and Catalase test according to Manual in Dairy Bacteriology, ICAR Sub-committee on Dairy Education (1972).

Skim milk (10\% TS) was prepared by dissolving $10.5 \mathrm{gm}$ of skimmed milk powder in $100 \mathrm{ml}$ of distilled water. $3.17 \mathrm{gm}$ of Whey protein concentrate was added into $100 \mathrm{ml}$ Skim milk (10\% TS) to maintain $13 \%$ TS. Fatless milk was heated up to $115^{\circ} \mathrm{C}$ for 15 min and cooled down to $38-40^{\circ} \mathrm{C}$. $1 \%$ Mixed culture of Lactobacillus acidophilus-015 and Lactobacillus casei-297 having 1:1 ratio was inoculated into the fatless milk and incubated for $7 \mathrm{~h}$ at $37^{\circ} \mathrm{C}$ after inoculation. The acidity was measured at $2 \mathrm{~h}$ interval during the incubation period of milk as per provision of 
ISI handbook of food analysis, part XI, Dairy products (1981).

Fifteen male albino rats (Wistar albino) of five to six weeks age with a body weight ranging from 135 to $140 \mathrm{gm}$ were purchased. All rats were initially given a standard diet of thirteen gm rat feed for one week before the treatment, purchased from Shankar Feed Pvt. Ltd, Biprannapara, Jalan Complex, Howrah, West Bengal.

Fifteen albino rats were randomly divided into three treatment groups with five rats in each group. All rats were caged individually and allowed to drink water from water bottle separately. All the rats were fed corresponding diet for forty-five days according to their groups. Which are given as follows:

Group I (Control): Basal diet

Group II (Treatment): Basal diet supplemented with fatless fermented milk.

Group III (Treatment): Basal diet supplemented with whey protein concentrated fortified fatless fermented milk

About $13 \mathrm{gm}$ of vet care rat feed was given to each rat individually of the group I. 4 gm of fatless fermented milk, which was prepared by inoculating probiotic cultures i.e. Lactobacillus acidophilus-015 and Lactobacillus casei-297, having 13\% TS from skim milk powder source, was given with 9 gm rat feed (vet care) per day to the group treatment-II rats separately. $9 \mathrm{gm}$ vet care rat feed, with $4 \mathrm{gm}$ whey protein concentrate added fatless fermented milk, prepared by inoculating probiotic cultures of Lactobacillus acidophilus-015 and Lactobacillus casei-297 having 10\% TS from skim milk powder source and 3\% TS from whey protein concentrate source, was given per day to the group treatment - III rats individually. On $0^{\text {th }}$ day the start of experiment, $15^{\text {th }}$ day $\& 30^{\text {th }}$ day during the experimental period and $45^{\text {th }}$ day the close of experiment, body weights of all albino rats were recorded by using an electronic balance. Faecal samples of albino rats were collected at $0,15,30$, and 45 days of feeding experiment. Wet faecal material was collected separately from each rat of different treatments and control group in a sterile 'clinicol' (HiMedia) container and brought to the laboratory for analysis.

One gram faeces were homogenized in $9 \mathrm{ml}$ of sterile normal saline solution and serially diluted according to desired dilution by using sterile one ml pipettes. Coliform count was done in accordance with the procedures laid down in Manual in Dairy Bacteriology by ICAR sub-committee on Dairy Education (1972). Blood samples were collected directly from the heart of control and treatment groups of rats on $0,15,30$ and 45 days of feeding experiment under the sedation of Ketamine hydrochloride (35 mg/Kg body weight; I.M). Blood samples were collected in dry test tubes and kept in slanting position for 2-3 h. Serum was separated and stored at $-20^{\circ} \mathrm{C}$ till estimation of Cholesterol. The total cholesterol level was estimated according to the method described by Wybenga and Pileggi method by using the diagnostic kits (span diagnostics, Surat).

Reagent1: Cholesterol Reagent.

Reagent 2: Working cholesterol standard, 200 $\mathrm{mg} \%$

Reagent 3: Precipitating Reagent

$3 \mathrm{ml}$ of Cholesterol reagent-1 was taken into blank (B), standard (S) and test (T) tubes each. Reagent-2 working cholesterol standard (200 $\mathrm{mg} \%$ ) about $0.015 \mathrm{ml}$ was added into standard tube (S). $0.015 \mathrm{ml}$ serum was taken into Test (T) tube by the help of micropipette. 
All the tubes were mixed well and kept immediately in the boiling water bath exactly for 90 seconds, immediately cooled to room temperature under running tap water. Required sample was taken in a quevete, and quevete was kept on a spectrophotometer to measure the optical density at $560 \mathrm{~nm}$.

Total Cholesterol $(\mathrm{mg} / \mathrm{dl})=\frac{\text { O.D Test }}{--------} \times 200$

Where,

O. $\mathrm{D}$ Test $=$ Optical Density of required sample

O. D Std = Optical Density of standard solution which was given by company span

\section{Results and Discussion}

Effects of feeding of whey protein concentrate fatless fermented milk to the experimental animal were recorded and analysed as follows:

\section{Effect on the lactic count in faecal materials}

Plain fatless fermented milk having $13 \%$ total solid was prepared by using $\mathrm{C}_{1}+\mathrm{C}_{2} \quad(1: 1)$ culture@1\% inoculum. Then WPC added fatless fermented milk (10\% TS from SMP and $3 \%$ T.S. from WPC) having $13 \%$ TS was prepared by inoculating @ $1 \%$ culture of $\mathrm{C}_{1}+\mathrm{C}_{2}$ (1:1). Rats were divided into three groups having five in each. Group - I was considered as control, Group-II and Group-III were taken as treatment group. Rat feed was fed to control group, PFFM was fed to GroupII and WFFM was fed to Group-III as treatment. Feeding experiment was continued up to forty-five days. At $0,15,30 \& 45$ days of feeding experiment, lactic count in faecal material was observed which is presented in
Table 1 and Figure 1. It can be observed that the increasing of lactic count in faecal materials of Group-II and Group-III rats were different from control group as well as from each other significantly $(\mathrm{P}<0.05)$ at each day of experiment, where as the lactic count in control group was almost remain same or slight changed during experimentation.

Lactic count in faecal material of Group II rats was increased as compare to control group. Yadav et al., (2008) reported that probiotic dahi containing L. acidophilus and L. casei significantly increased counts of Lactobacilli adherent to epithelial walls and free in the lumen of the small and large intestine. So the increment of lactic count in Group-II rats was observed. Naidu et al., (1999) suggested that whey contains Lactose, Immunoglobulin, Lactoferrin, Lactoperoxidase, Glycomacropeptides and Sphingoloipids which survive the passage through the stomach and act as prebiotic agent. Hence by addition of WPC into fatless fermented milk, the lactose composition be increased and also the above ingredient level. By increasing of the above mentioned ingredients, which provide good source of nutrients to Lactic acid bacteria, the population and viability of lactic acid bacteria may be increased. Thus by taking of such WPC added fatless fermented milk regularly more lactic acid bacteria in vivo may be seen and thereby more number of Lactic count might be obtained in faecal materials of Group-III rats among the groups.

\section{Effect on the coliform count in faecal materials}

At $0,15,30,45$ days of experiments, coliform count in faecal material to corresponding group of rats was observed which is presented in Table 2 and Figure 2. 
Table.1 Lactic acid bacteria count (c.f.u $\times 10^{5} /$ gm) in faecal materials of different groups of rat

\begin{tabular}{|c|c|c|c|c|}
\hline \multirow{2}{*}{ Group } & \multicolumn{5}{|c|}{ Day } \\
\cline { 2 - 5 } & $\mathbf{0}$ & $\mathbf{1 5}$ & $\mathbf{3 0}$ & $\mathbf{4 5}$ \\
\hline I & $78.80 \pm 5.45$ & $84.20 \pm 3.44$ & $82.60 \pm 2.42$ & $\mathbf{8 9 . 8 0} \pm \mathbf{2 . 8 5}$ \\
\hline II & $75.80 \pm 4.29$ & $358.00 \pm 20.83$ & $724.00 \pm 35.30$ & $982.00 \pm \mathbf{1 7 . 1 5}$ \\
\hline III & $79.40 \pm 5.20$ & $\mathbf{5 0 0 . 0 0 \pm 2 8 . 8 1}$ & $\mathbf{8 8 8 . 0 0} \pm \mathbf{2 4 . 5 8}$ & $\mathbf{1 1 5 4 . 0 0 \pm 4 6 . 6 5}$ \\
\hline
\end{tabular}

(Average of five replications)

Table.2 Coliform count (c.f.u $\times 10^{2} / \mathrm{gm}$ ) in faecal materials of different groups of rat

\begin{tabular}{c|c|c|c|c|} 
Group & \multicolumn{4}{|c|}{ Day } \\
\cline { 2 - 5 } & $\mathbf{0}$ & $\mathbf{1 5}$ & $\mathbf{3 0}$ & $\mathbf{4 5}$ \\
\hline I & $3860.00 \pm 169.12$ & $4100.00 \pm 343.51$ & $4100.00 \pm 277.49$ & $\mathbf{3 9 8 0 . 0 0 \pm 4 5 5 . 4 1}$ \\
\hline II & $4340.00 \pm 273.13$ & $802.00 \pm 40.67$ & $410.00 \pm 28.98$ & $73.80 \pm 3.89$ \\
\hline III & $4820.00 \pm 515.17$ & $\mathbf{5 7 6 . 0 0} \pm 45.01$ & $266.00 \pm 18.60$ & $\mathbf{4 1 . 4 0 \pm 2 . 8 6}$ \\
\hline
\end{tabular}

(Average of five replications)

Table.3 Serum cholesterol level (mg/dl) of different groups of Albino rat

\begin{tabular}{|c|c|c|c|c|} 
Group & \multicolumn{5}{|c|}{ Day } \\
\cline { 2 - 5 } & $\mathbf{0}$ & $\mathbf{1 5}$ & $\mathbf{3 0}$ & $\mathbf{4 5}$ \\
\hline \hline I & $72.85 \pm 0.47$ & $76.00 \pm 0.41$ & $79.93 \pm 0.89$ & $\mathbf{8 6 . 9 3} \pm \mathbf{2 . 3 8}$ \\
\hline II & $73.88 \pm 3.50$ & $66.71 \pm 2.46$ & $60.49 \pm 2.28$ & $\mathbf{5 4 . 0 8} \pm 1.90$ \\
\hline III & $\mathbf{8 2 . 4 1} \pm \mathbf{3 . 2 6}$ & $\mathbf{6 7 . 4 4} \pm \mathbf{2 . 9 6}$ & $\mathbf{5 6 . 2 3} \pm 1.98$ & $\mathbf{4 4 . 3 2} \pm 1.50$ \\
\hline
\end{tabular}

(Average of five replications)

Table.4 Body weight (gm) of different groups of Albino rat

\begin{tabular}{c|c|c|c|c|} 
Group & \multicolumn{5}{|c|}{ Day } \\
\cline { 2 - 5 } & $\mathbf{0}$ & $\mathbf{1 5}$ & $\mathbf{3 0}$ & $\mathbf{4 5}$ \\
\hline I & $137.20 \pm 0.86$ & $157.20 \pm 1.07$ & $178.40 \pm 1.21$ & $199.60 \pm 1.44$ \\
\hline III & $137.60 \pm 0.87$ & $170.80 \pm 0.86$ & $199.40 \pm 1.50$ & $221.80 \pm 1.16$ \\
\hline III & $137.80 \pm 0.86$ & $180.20 \pm 1.16$ & $211.60 \pm 1.08$ & $240.40 \pm 1.03$ \\
\hline
\end{tabular}

(Average of five replications) 
Fig.1 Change in lactic acid bacteria count in faecal materials

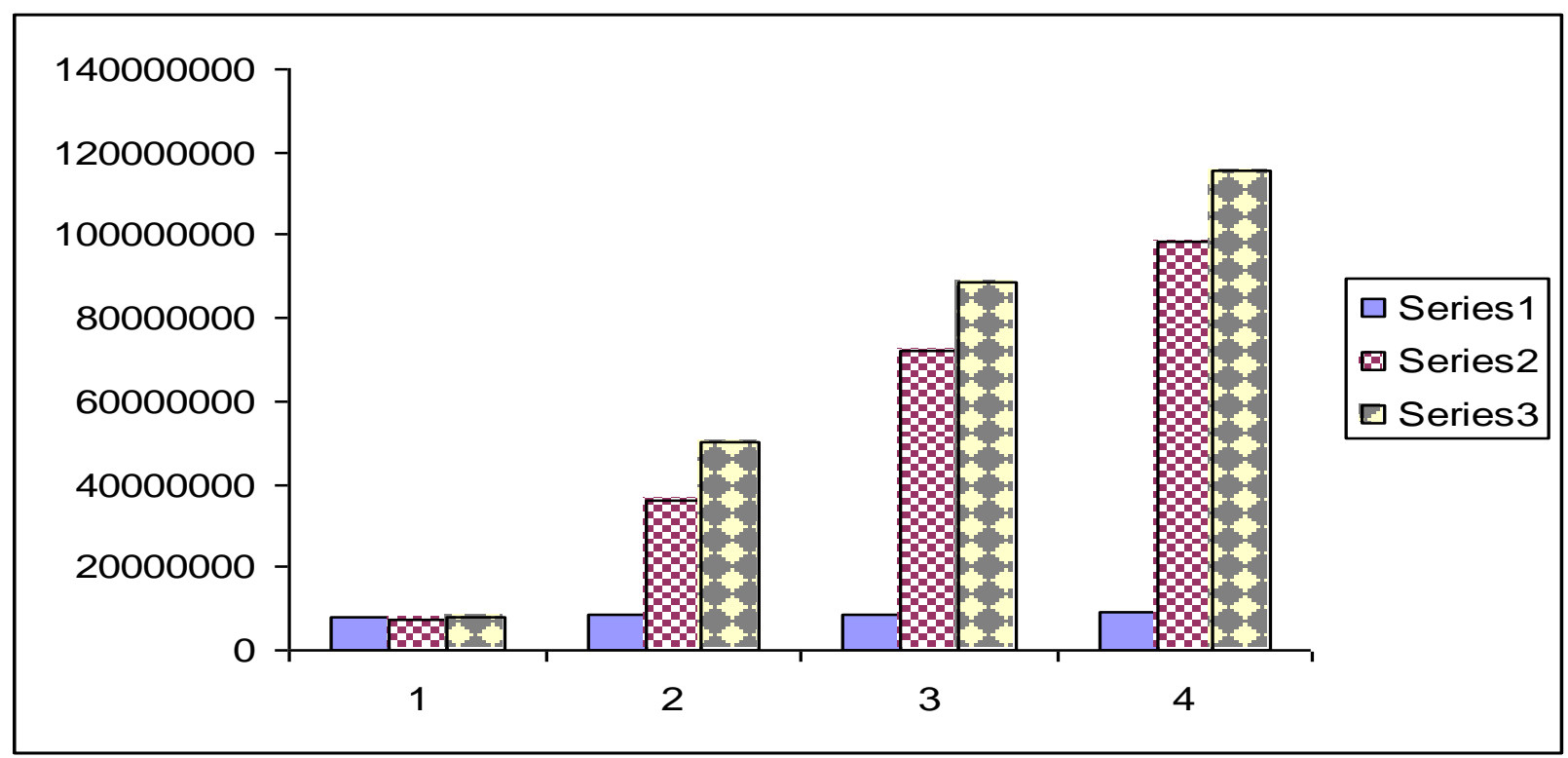

Series -1 is Group I, Series -2 is Group II and Series 3 is Group III

1 stands for 0 day, 2 for 15 day, 3 for 30 day and 4 for 45 day.

Fig.2 Change in coliform count in faecal materials

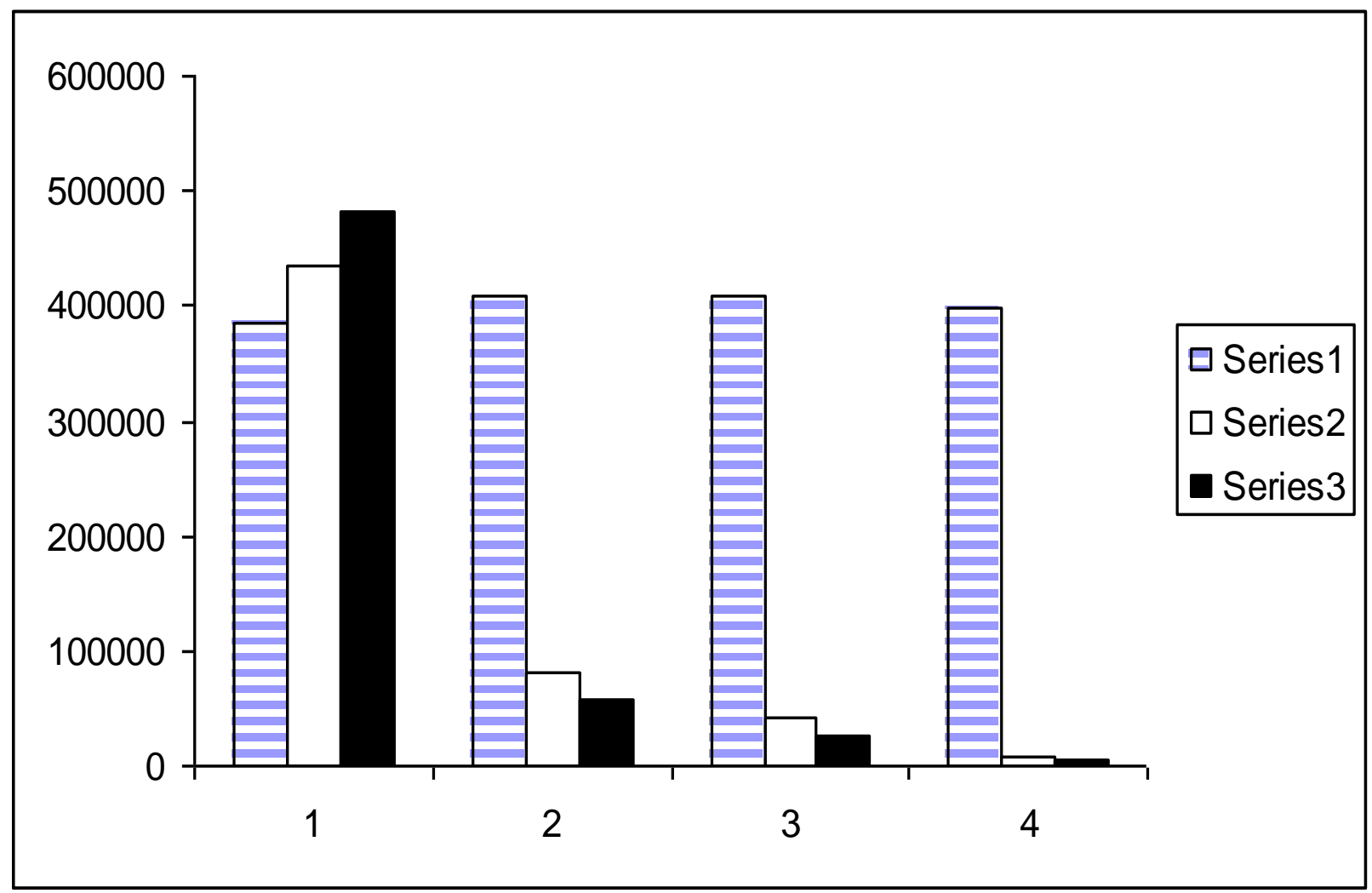

Series -1 is Group I, Series - 2 is Group II and Series 3 is Group III 1 stands for 0 day, 2 for 15 day, 3 for 30 day and 4 for 45 day. 
Fig.3 Change in serum cholesterol level

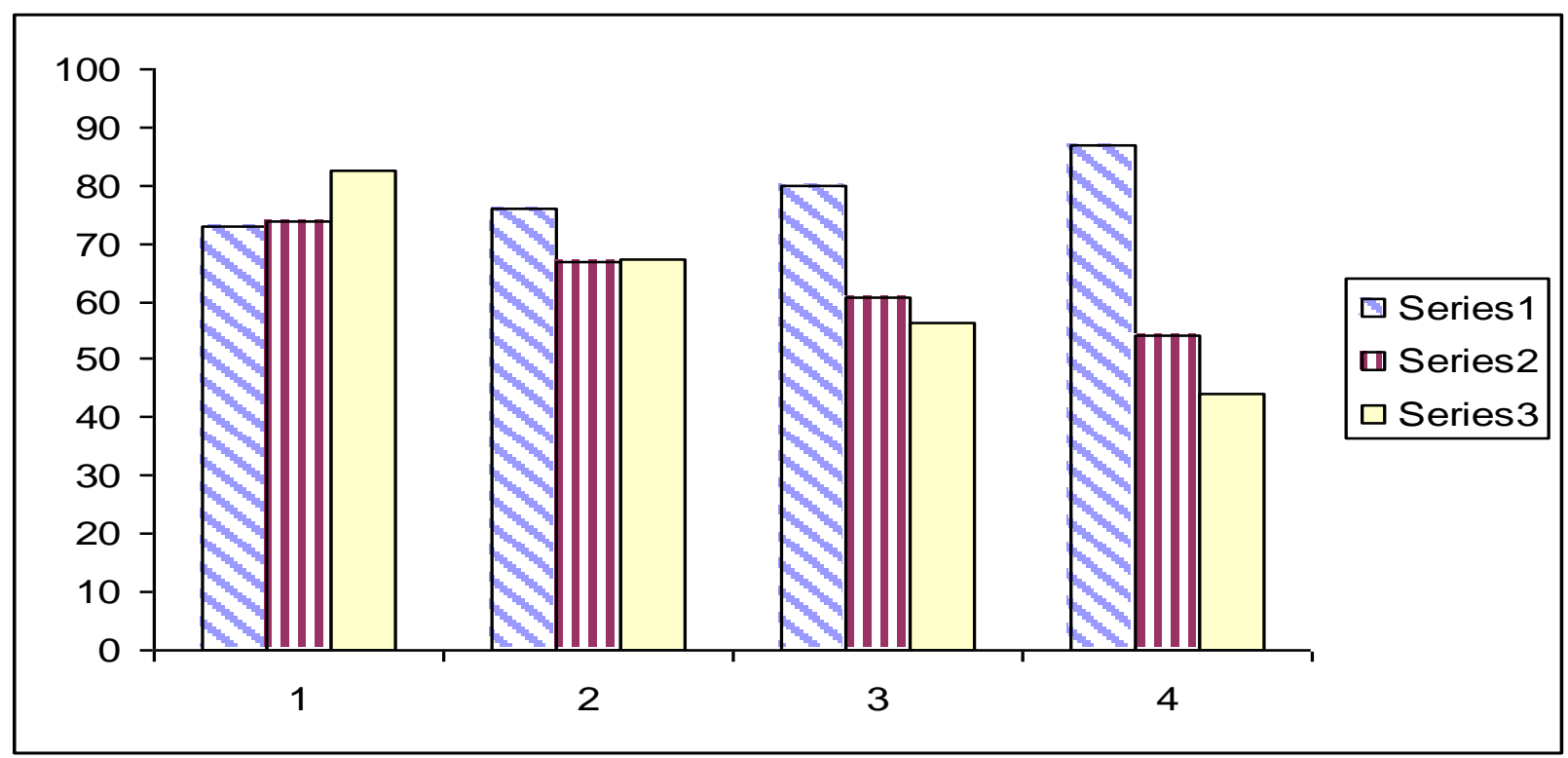

Series -1 is Group I, Series -2 is Group II and Series 3 is Group III 1 stands for 0 day, 2 for 15 day, 3 for 30 day and 4 for 45 day.

Fig.4 Change in body weight

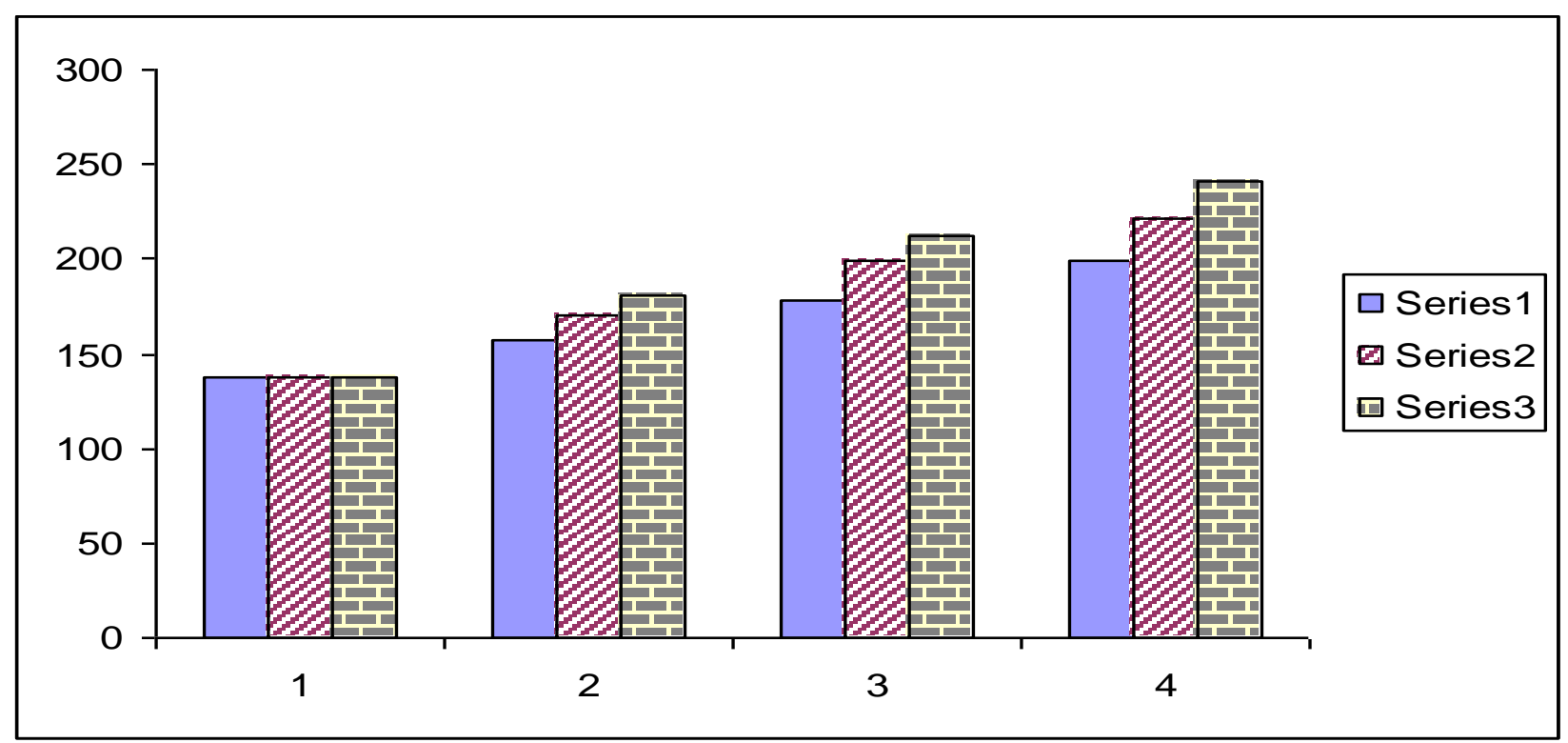

Series -1 is Group I, Series - 2 is Group II and Series 3 is Group III 1 stands for 0 day, 2 for 15 day, 3 for 30 day and 4 for 45 day.

The colifom count was declining significantly $(\mathrm{p}<0.05)$ in faecal materials in Group-II and Group-III rats where as in control group constant or increase trend was observed. Alojz Bonma Radomie et al.,
(2002) suggested that production of bacteriocin like substances or competitive exclusion that involved the ability of bifidobacteria to occupy binding sizes on intestinal wall inhibited the coliform or other 
intestinal pathogens, thereby prevented attachment and growth of enteric pathogens competing for nutrients and stimulation of immunity. Yadav et al., (2008) suggested that the number of coliforms in faeces of experimental diabetic animals was decreased after feeding of probiotic dahi. Klaenhammer (1998) found that Lactobacillus acidophilus produces variety of antimicrobial compounds like lactic acid (>85\%), hydrogen peroxide and bacteriocins viz. Lactacin B, Acidophilucin A, Acidocin A, Acidocin 8912 and Acidocin B etc. which have the ability against pathogenic microorganisms.

So we agree with the above reasons that the coliform count in faecal material was decreased due to the antibacterial activity of such taken probiotic microorganisms. Hence the coliform count was significantly decreased in case of Group II albino rats as compare to control Group-I. Coliform count in faecal materials of Groups-III rats was decreased significantly as compare with Group II and control Group-I rats. Because according to Newburg et al., (1998) whey protein concentrate has natural killer cell activity against pathogens. Thus incase of Group-III rats, coliform count in faecal materials was decreased significantly as compare to Group-II and Group-I albino rats.

\section{Effect on the total cholesterol level of rats}

At $0,15,30,45$ days of experiments, total cholesterol level to the corresponding group of rats were observed, which is presented in Table 3 and shown in Figure 3. It may be observed that the decreasing trend of total cholesterol level of Group II and Group III rats was significant as compare with control Group and the rate of decreasing is more in Groups-III significantly as compare to Group II at each day of experiment, whereas cholesterol level was increased gradually incase of control group rats.

Total cholesterol level in Group II and Group III rats were decreased and significantly from each other. Kawase et al., (2000) suggested that serum cholesterol might be lowered in experimental animal due to the effect of the fermentation product on cholesterol metabolizing enzyme system in liver, the promotion of excretion of cholesterol through faeces, the inhibition of cholesterol absorption by the binding of cholesterol to lactic acid bacteria cells, the promotion of excretion by the binding of bile acid to lactic acid bacterial cells and the assimilation of cholesterol by lactic acid bacteria. Cholesterol level was decreased in both treatment Groups might be because of the above said reason. But the total cholesterol level was decreased significantly more in Group III than Group II because Group III rats were fed WPC added fatless fermented milk whereas Group II rats were fed plain fatless fermented milk. As $\beta$ lactoglobulin (a component of WPC) inhibited cholesterol absorption through changes of micellar cholesterol solubility in the intestine, accompanied by an increase of faecal steroid excretion (Nagaoka, 1996). So WPC added fatless fermented milk had better effect against cholesterol level on blood serum as compare to plain fatless fermented milk fed animals.

\section{Effect on the body weight}

The data related to body weight of rats of corresponding group at $0,15,30,45$ days of experiments were observed and presented in Table 4 and in Figure 4. It may be observed that the body weight of all groups of rat were increased but body weight was increased more significantly in case of Groups-III rats than that of Group-II and control Group. 
Body weight was more increased in GroupII and Groups- III rats than control Group because of more availability of nutrition through fatless fermented milk. Rasic (1987) found that the body weight of rats, fed with diet containing cultured dairy product was increased because of nutrient utilization enhancement associated with availability of more digestible protein as well as enhanced bio-availability of minerals, especially iron and synthesis of B-complex Vitamins, particularly folic acid. But the gaining of body weight was significantly more in Group III than Group II rats because Group III rats were fed WPC added fatless fermented milk where as Groups II rats were fed plain fatless fermented milk. According to Walzem et al., (2002) whey protein content about $26 \%$ of branched chain amino acids which stimulated protein synthesis and muscle building in experimented animal. The mineral content of fat less fermented milk was increased by adding of WPC. Hence due to these reasons body weight of Group III rats was increased more than Groups II rats.

An investigation was planned and conducted for preparation of fatless fermented milk and arbitrarily add the quantity of WPC into fat less fermented milk as well as to study the effect of administration of fat less fermented milk containing whey protein concentrate to Albino rats for determining the prebiotic effect of whey protein concentrate. Two cultures named Lactobacillus acidophilus015 $\left(\mathrm{C}_{1}\right)$ and Lactobacillus casei-297 $\left(\mathrm{C}_{2}\right)$ were inoculated @ 1\% for preparation of fatless fermented milk having $13 \%$ TS. $\mathrm{C}_{1}+$ $\mathrm{C}_{2}$ with 1:1 ratio by adding whey protein concentrate $3 \%$ in such a way that the total solid remained $13 \%$ in fat less fermented milk. Lactic count was more increased in Group III rats as compare to Group II followed by control group-I rats at the end of experiment. Coliform count in faecal material was declined more in Group III rats than Group II rats and in Group II rats the coliform count was decreased than control Group-I rats. Serum cholesterol was more decreased in Groups III rats than Group II rats and in case of Group II rat's serum cholesterol was decreased as compare to initial level of experiment whereas cholesterol level was increased in control group rats at the end of the experiment. On the basis of this experiment it can be conclude that the addition of prebiotic as WPC (Level $=3 \%$ ) to probiotic for the preparation of fatless fermented milk has remarkable increase in the lactic count, decrease in coliform count in faeces, decrease cholesterol in blood serum and dramatically increase in the body weight of rats. Therefore it can be recommended to use of WPC as prebiotic in the preparation of fat less fermented milk products for maintaining the bacterial environment of intestine and controlling blood cholesterol level.

\section{References}

Alojz Bonma Radomir N, Dagmar M, Peter $\mathrm{G}$ 2002. The possibilities of potentiality and the efficacy of probiotics. Trends in Food Science and Technology 13: 121-126.

Chemical examination of milk. ISI Handbook of Food Analysis, Part XI, dairy Products, 1981.

Gram's Method of staining bacteria. Manual in Dairy Bacteriology, ICAR, NDRI Press/ 213-78/9-79/1000 1972.

Kawase M, Hashimoto H, Hosoda M, Morita H, Hosono A 2000. Effect of administration of fermented milk containing whey protein concentrate to rats and healthy men on serum lipids and blood pressure. Journal of dairy science 83: 255-263. 
Klaenhammer TR 1998. Functional activities of Lactobacillus probiotics: genetic mandate. Int. Dairy Journal 8: 497-506.

Klaver FAM, Van der Meer R 1993. The assumed assimilation of cholesterol by lactobacilli and Bifidobacterium bifidum is due to their bile saltdeconjugating activity. Appl Environ Microbiol 59: 1120 - 1124.

Nagaoka S 1996. Studies on regulation of cholesterol metabolism induced by dietary food constituents or xenobiotics. J Jpn Soc Nutr Food Science 49: 303-313.

Naidu AS, Didlack WR, Clemens RA 1999. Probiotic spectra of lactic acid bacteria Crit Rev Food Sci Nutr 38: 13 - 126.

Newburg DS, Peterson JA, Ruiz-Palacios GM, Maison DO, Morrow AL, Shults J, Guerrero ML, Chaturvedi P, Newburg SO, Scallan CD, Taylor MR, Ceriani RL, Pickering LK 1998. Role of human milk lactoferrin in protection against symptomatic rotavirus infection. Lancet 351: 1160 -1164.

Oyetayo VO, Adetuyi FC, Akinyosoye FA 2003. Safety and protective effect of Lactobacillus acidophilus and Lactobacillus casei used as probiotic agent in vivo. African journal of Biotechnology 2: 448-452.

Presumptive coliform test, Manual in Dairy Bacteriology, ICAR, NDRI Press/ 213-78/9-79/1000. 1972.
Rasic JR 1987. Nutritive value of yogurt. Cultured Dairy Products Journal 22: 69.

Robinson RK, Batt CA, Patel PD 2000. Lactobacillus acidophilus pub. In Encyclopedia of food microbiology. Vol. 2, PP. Academic press, New York. Page: 1151 -1157.

Robinson RK, Batt CA, Patel PD 2000. Lactobacillus casei pub. In Encyclopedia of food microbiology. Vol. 2, PP. Academic press, New York. Page: 1157-1164.

Salminen S, Ouwehand A, Benno Y, Lee YK 1999. Probiotics: How should they be defined? Trends in food Science and Technology 10: 107-110.

Walzem RL, Dillard CJ, German JB 2002. Whey components: Millennia of evolution create functionality for mammalian nutrition: what we know and what we may be overlooking. Crit Rev Food Sci Nutr 42: 353 - 372.

Wybenga DR, Pileggi 1970. One step method for the in vitro determination of cholesterol in serum/ plasma. J. Clinical Chemistry 16: 980.

Yadav H, Jain S, Sinha PR 2008. The effect of probiotic dahi containing Lactobacillus acidophilus and Lactobacillus casei on Gastropathic consequences in Diabetic Rats. J Med Food 11: 62-68.

\section{How to cite this article:}

Bisoi, P.K., Rakesh Kumar, Binita Rani and Singh, B.K. 2018. Effect of Administration of Fatless Probiotic Food Containing Whey Protein Concentrate on the Faecal Count, Blood Cholesterol Level and Growth Performance of Albino Rats. Int.J.Curr.Microbiol.App.Sci. 7(02): 200-209. doi: https://doi.org/10.20546/ijcmas.2018.702.025 